\title{
镍催化环加成反应的研究进展
}

\author{
曾中一杨定乔* \\ (华南师范大学化学与环境学院 广州 510006)
}

摘要 综述了近年来镍催化环加成反应的研究进展, 主要包括[3+2]和 $[2+2+2]$ 环加成反应及部分关于 $[4+2],[3+$ $2+2],[4+2+2],[2+2]$ 等环加成反应的报道, 并对部分环加成反应可能的机理进行了讨论.

关键词 镍催化; 环加成反应; 研究进展

\section{Progress in Nickel-Catalyzed Cycloaddition Reactions}

\author{
Zeng, Zhongyi $\quad$ Yang, Dingqiao* \\ (School of Chemistry and Environment, South China Normal University, Guangzhou 510006)
}

\begin{abstract}
The recent progress in nickel-catalyzed cycloaddition reactions is reviewed, mainly including $[3+2]$ and $[2+2+$ 2] cycloaddition reactions. Besides, several nickel-catalyzed [4+2], $[3+2+2],[4+2+2]$ and $[2+2]$ cycloaddition reactions are introduced. Moreover, the possible mechanisms of some parts of cycloaddition reactions are also discussed.

Keywords nickel-catalyzed; cycloaddition reaction; research progress
\end{abstract}

环加成反应(Cycloaddition Reaction)是两个共轭体 系结合成环状分子的一种双分子反应，它是由两个或多 个不饱和化合物(或同一化合物的不同部分)结合生成环 状加合物, 并伴随有系统总键级数减少的化学反应. 这 类反应是合成单环及多环化合物的一种重要方法. 有关 环加成反应最早是德国化学家 Diels 与其学生 Alder 等 ${ }^{[1]}$ 在 1928 年通过环戊二烯与顺丁烯二酸䣶发生[4+2]环 加成实现的. 常见的环加成反应类型除 $[4+2]$ 外, 还包 括[3+2], [2+2+2], [3+2+2], [4+2+2]等. 环加成反 应的主要特点是可以将不饱和链状化合物直接转变成 环状化合物, 包括三元、四元到九元、十元环等, 且原 子利用率高. 在天然产物的全合成、药物化学等领域有 着广泛的应用. 例如: 通过 1,3-偶极环加成得到了作为 $\beta$-内酰胺酶抑制剂的他唑巴坦 ${ }^{[2]}$ 和具有杀菌活性的异噁 唑啉化合物 ${ }^{[3]}$; 徐显秀等 ${ }^{[4]}$ 采用 $[2+2]$ 环加成反应合成 得到的加巴喷丁 (Gabapentin) 是一种主要用于治疗癫㾁 及多种神经性疼痛的药物; Heller 等 ${ }^{[5]}$ 成功将 $[2+2+2]$ 环加成应用于 Vitamin $\mathrm{B}_{6}$ 的全合成, 环加成反应的产率 可达 $86 \%$; 最近余志祥等 ${ }^{[6]}$ 发现新型的 $[3+2+1]$ 环加 成, 并以此反应作为关键的一步, 完成了沉香呋喃类天
然产物( \pm )- $\alpha$-Agarofunan 的全合成.

近几十年来, 过渡金属以其特有的催化活性吸引了 大批研究者的关注. 将过渡金属催化剂应用于环加成反 应是有机金属化学研究的热点之一, 许多需要加热、光 照等特殊条件才能发生的环加成反应, 加入金属催化剂 后在温和条件下即可实现, 并且可以获得较高的产率和 较好的选择性. 目前对镍催化环加成反应的研究主要集 中在 $[3+2],[2+2+2],[4+2]$ 等, 还有少量 $[3+2+2]$, $[4+2+2],[2+2],[2+2+1],[2+2+2+2],[4+3+2]$ 等环加成反应方面的报道. 使用镍配合物催化环加成反 应具有催化剂廉价易得、对映选择性高、转化率高等优 点, 这对于手性药物及天然产物的全合成具有一定的科 学意义和应用前景.

\section{1 [3+2]环加成}

过渡金属催化 $1,3-$-偶极体与碳碳重键的环加成反 应, 即 1,3-偶极环加成反应, 是合成天然产物和药物中 常见的五元杂环结构的重要方法 ${ }^{[7]}$. 此外, 还报道过用 (杂)环丙烷作三原子单元, 在镍催化作用下与碳碳重键 进行的 $[3+2]$ 环加成.

\footnotetext{
*E-mail: yangdq@scnu.edu.cn

Received January 28, 2013; revised April 27, 2013; published online May 8, 2013. ince (No. 8251063101000002).

国家自然科学基金(Nos. 21172081, 21372090)和广东省自然科学基金(No. 8251063101000002)资助项目.
}

Project supported by the National Natural Science Foundation of China (Nos. 21172081, 21372090) and the Natural Science Foundation of Guangdong Prov- 


\section{1 甲亚胺叶立德参与的[3+2]环加成}

甲亚胺叶立德 (以亚胺酯作为前体)与活性烯烃的环 加成反应可以合成具有多个手性中心的吡咯烷骨架结 构. 2005 年, $\mathrm{Grigg}$ 等 ${ }^{[8]}$ 尝试用手性双膦配体 $\mathbf{1}, 2$ 与 $\mathrm{NiCl}_{2}$ 组成催化体系催化亚甲胺叶立德 $3 a$ 与烯丙酸甲酯进行 [3+2]环加成反应(Eq. 1), 产率虽高达 92\%, 但产物为 外消旋体. 这表明手性双膦配体先从催化体系中解离出 来，剩下游离的 $\mathrm{Ni}(\mathrm{II})$ 催化反应.

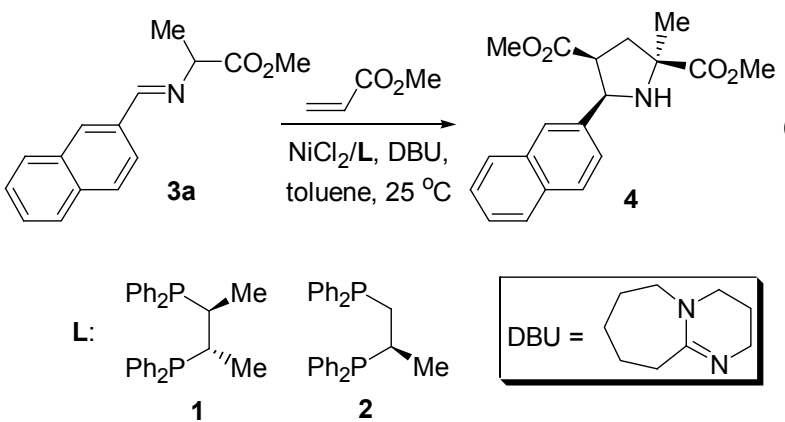

2008 年, 中国科学院上海有机化学研究所施敏等 ${ }^{[9]}$ 改用轴手性联菜二亚胺(BINIM)型化合物 5 作为手性配 体, 研究了 $N$-芳基马来酰亚胺 $\mathbf{6}$ 与甲亚胺叶立德 $\mathbf{3}$ 的成 环反应，得到 endo 构型产物 7 (Eq. 2). 值得一提的是, 3 和 6 苯环上带有不同的吸电子或供电子基团时, 反应结 果均令人比较满意, 并且取代基的位置对环加成产物的 影响也不明显(表 1). 值得注意的是, 吡啶环和亚胺上的 氮原子对催化体系的催化活性不可或缺.<smiles>CC(=O)C1NC([Al])C2CN([Al])CC12</smiles>

7 (endo)

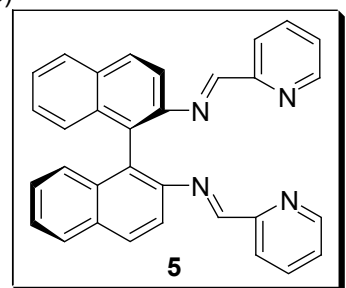

基于上述研究结果, 施敏等认为甲亚胺叶立德 $\mathbf{3}$ 先 与催化剂结合得到六配位络合物 $\mathbf{8}$, 然后 $N$-苯基马来酰 亚胺从背面进攻形成过渡态 $\mathbf{9}$, 因而得到 endo 构型产物 (Eq. 3).
表 1 底物 3 和 6 中不同取代基对环加成反应的影响

Table 1 Effect of different substituents of substrates $\mathbf{3}$ and $\mathbf{6}$ on cycloaddition reactions

\begin{tabular}{ccccc}
\hline Entry & $\mathrm{Ar}$ & $\mathrm{Ar}^{1}$ & $\mathrm{Yield} / \%$ & $e e / \%$ \\
\hline 1 & $p-\mathrm{CH}_{3} \mathrm{C}_{6} \mathrm{H}_{4}$ & $\mathrm{Ph}$ & 84 & 84 \\
2 & $o-\mathrm{BrC}_{6} \mathrm{H}_{4}$ & $\mathrm{Ph}$ & 82 & 85 \\
3 & $m-\mathrm{BrC}_{6} \mathrm{H}_{4}$ & $\mathrm{Ph}$ & 80 & 82 \\
4 & $p-\mathrm{BrC}_{6} \mathrm{H}_{4}$ & $\mathrm{Ph}$ & 86 & 89 \\
5 & $1-\mathrm{Naphthyl}$ & $p-\mathrm{CH}_{3} \mathrm{OC}_{6} \mathrm{H}_{4}$ & 82 & 90 \\
6 & 1-Naphthyl & $p-\mathrm{FC}_{6} \mathrm{H}_{4}$ & 83 & 86 \\
\hline
\end{tabular}

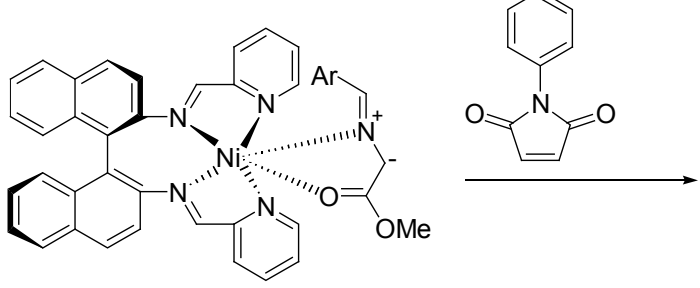

hexacoordinated $\mathrm{Ni}(\mathrm{II})$ complex 8

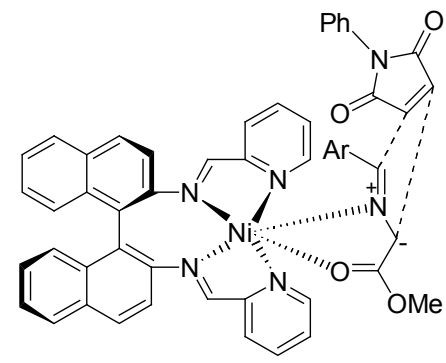

transition state 9

2010 年, Arai 等 ${ }^{[10]}$ 探讨了镍催化反式硝基烯烃与甲 亚胺叶立德 3 的环加成反应，利用固相催化/CD-HTS(圆 二色谱-高效耖选)系统篎选出最有效的配体 10, 主要得 到 exo'构型产物 11 (Eq. 4). 值得一提的是，偶极体 $\mathbf{3}$ 芳 环上带有吸电子或供电子基团，对反应的选择性(包括 非对映选择性和对映选择性)影响不明显. 此外脂肪族 硝基烯烃亦可转化成相应的环状产物，且对映选择性仍 较高，只是产率和非对映选择性稍有降低.

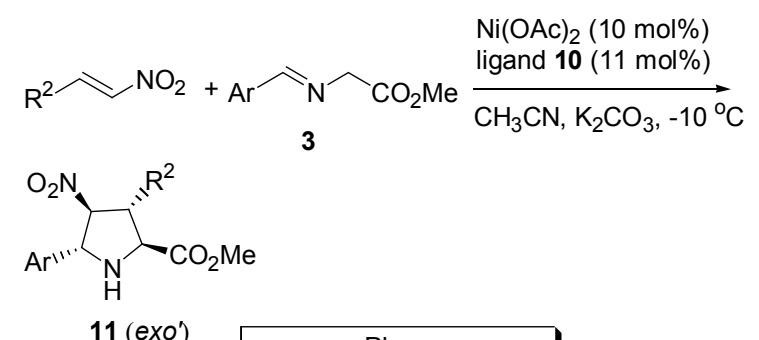


基于主要产物为 $e x o^{\prime}$ 构型, Arai 等提出了可能的反 应机理(Scheme 1): 首先亚胺叶立德与 $\mathrm{Ni}$ (II)催化剂配 位得到 12, 12 作为亲核试剂进攻硝基烯烃的 2-C 发生反 式 Michael 加成形成环状中间体 13, 然后开环得到 14, 旋转 14 中 $\mathrm{C}-\mathrm{N}$ 键以得到更加稳定的过渡态 15 , 随后 发生分子内 Mannich 反应, 一方面得到较稳定的 $e x o^{\prime}$ 构 型异构体 11, 另一方面释放出 $\mathrm{Ni}(\mathrm{II})$ 催化剂, 整个催化 反应得以循环进行.

\section{2 硝酮参与的 $[3+2]$ 环加成}

硝酮与碳碳双键的 $1,3-$-偶极环加成是构建异噁唑环 骨架非常有效的方法. 2005 年, Suga 等 ${ }^{[1]}$ 报道了以 (R)-BINIM-DCOH (16)作手性配体, 镍催化硝酮 17 与噻 唑烷硫酮 18 发生环加成反应(Eq. 5), 得到 exo 构型产物, 产率 35\% 98\%, 非对映选择性和对映选择性均比较理 想, 最高分别可达 $99 ： 1$ 和 95\% ee.
Suga 研究小组发现, 当硝酮中 $C$-和 $N$-苯环上带有 吸电子或供电子基团时, 反应结果均令人比较满意. 值 得一提的是, $C$-苯基- $N$-烷基和 $C, N$-二烷基硝酮也可进 行成环反应，且对映选择性和非对映选择性仍较高，只 是产率有所降低.

2011 年, 四川大学冯小明等 ${ }^{[12]}$ 尝试以 $N, N^{\prime}$ 二二氧化 合物 20 为手性配体，探讨硝酮 17 与亚烷基丙二酸酯 21 的环加成反应(Eq. 6). 研究发现：镍盐中对应的阴离子 对催化剂的催化活性影响极大, 其中 $\mathrm{Ni}\left(\mathrm{ClO}_{4}\right)_{2}$ 的催化 活性最高. 值得一提的是, 17 碳上取代基 $\mathrm{R}^{1}$ 为连有拉电 子或供电子基团的芳环时, 对反应结果影响不大; 但 17 氮上的取代基 $\mathrm{R}^{2}$ 为烷基时，产物的产率明显降低. 同 时, 21 亚烷基上的取代基 $\mathrm{R}^{3}$ 为连有拉电子或供电子芳 环时, 对环加成产物的影响也不明显(表 2).

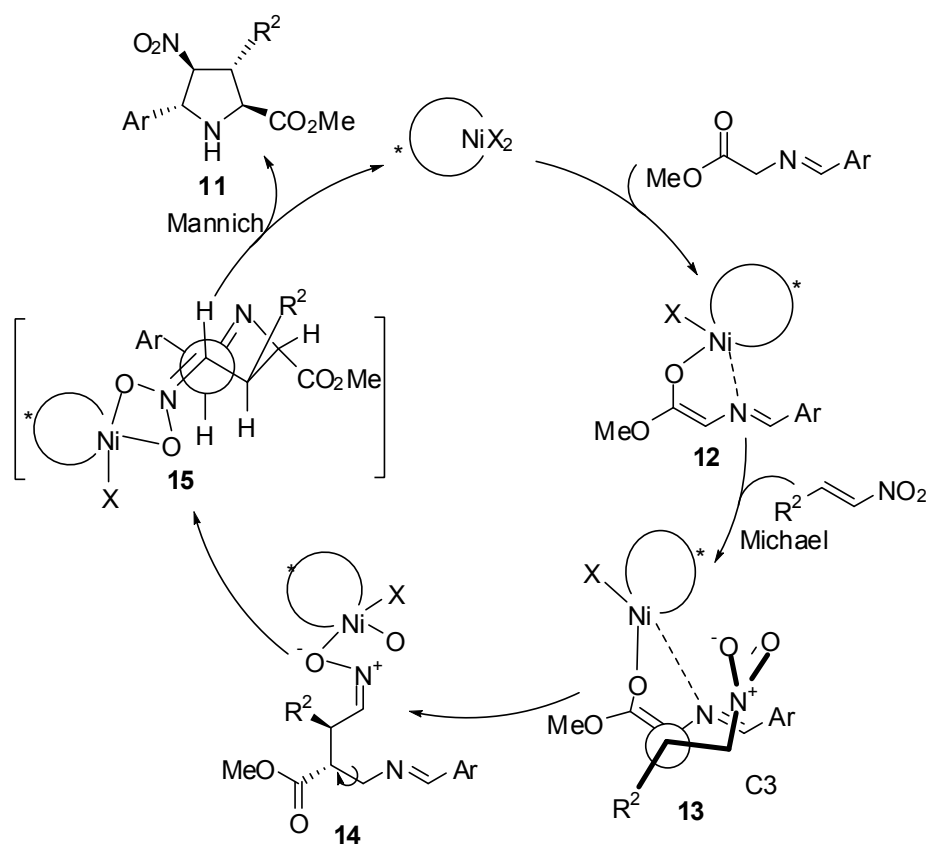

Scheme 1

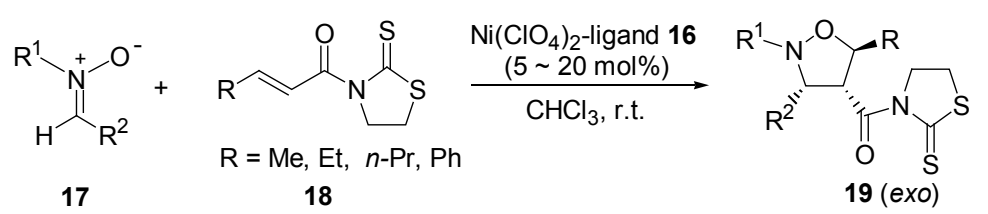




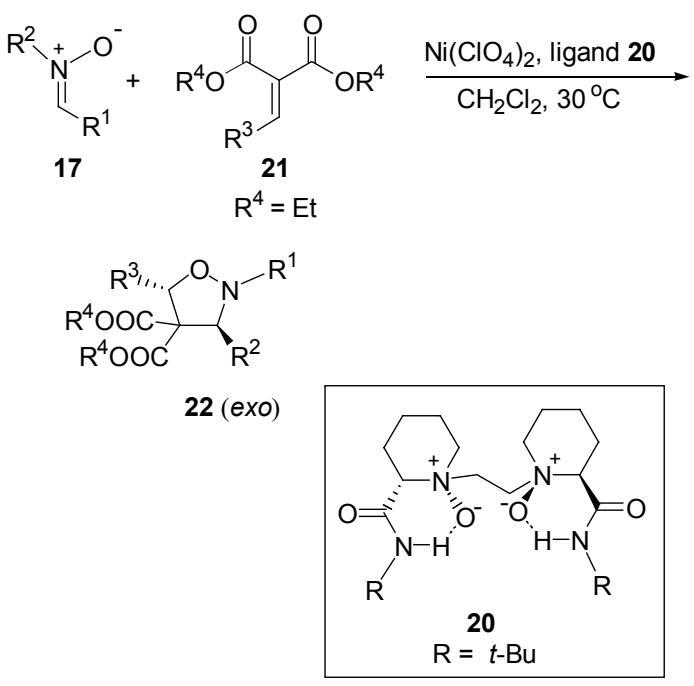

表 2 底物 17 和 21 中不同取代基对环加成反应的影响

Table 2 Effect of different substituents of substrates $\mathbf{1 7}$ and $\mathbf{2 1}$ on cycloaddition reactions

\begin{tabular}{|c|c|c|c|c|c|c|}
\hline Entry & $\mathrm{R}^{1}$ & $\mathrm{R}^{2}$ & $\mathrm{R}^{3}$ & Yield/\% & $d r$ & $e e / \%$ \\
\hline 1 & $\mathrm{Ph}$ & $\mathrm{Ph}$ & $\mathrm{Ph}$ & 94 & $93: 7$ & 99 \\
\hline 2 & $p-\mathrm{BrC}_{6} \mathrm{H}_{4}$ & $\mathrm{Ph}$ & $\mathrm{Ph}$ & 83 & $95: 5$ & 98 \\
\hline 3 & $p-\mathrm{CH}_{3} \mathrm{OC}_{6} \mathrm{H}_{4}$ & $\mathrm{Ph}$ & $\mathrm{Ph}$ & 80 & $99: 1$ & 97 \\
\hline 4 & $\mathrm{Ph}$ & $\mathrm{Me}$ & $\mathrm{Ph}$ & 54 & $99: 1$ & 94 \\
\hline 5 & $\mathrm{Ph}$ & $\mathrm{Ph}$ & $p-\mathrm{BrC}_{6} \mathrm{H}_{4}$ & 91 & $98: 2$ & 97 \\
\hline 6 & $\mathrm{Ph}$ & $\mathrm{Ph}$ & $p-\mathrm{CH}_{3} \mathrm{OC}_{6} \mathrm{H}_{4}$ & 86 & $96: 4$ & 97 \\
\hline
\end{tabular}

基于上述研究结果，冯小明等提出了一种可能的反 应过渡态 23, 由于硝酮 $17 \mathrm{a}$ 碳上苯环与 23 中叔丁基的 空间排斥, 有利于 $17 \mathrm{a}$ 从背面进攻过渡态 23 得到 exo 构 型产物 22a (Scheme 2).

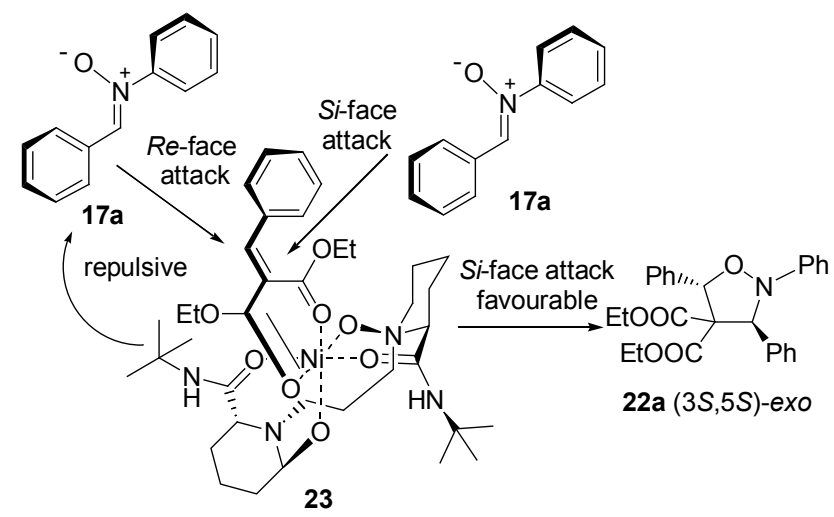

Scheme 2

\section{3 氧化腈参与的 $[3+2]$ 环加成}

氧化腈(以相应的氯化肪作前体)与碳碳双键的成环 反应是合成异噁唑啉环骨架结构的常用方法. 2004 年, Sibi 等 ${ }^{[13]}$ 研究了镍催化氧化腈 24 与吡唑烷酮 25a 的环 加成反应(Eq. 7). 以双噁唑啉化合物 26 作手性配体, 环 加成产物的产率和对映选择性分别达 74\%和 $92 \%$ ee.

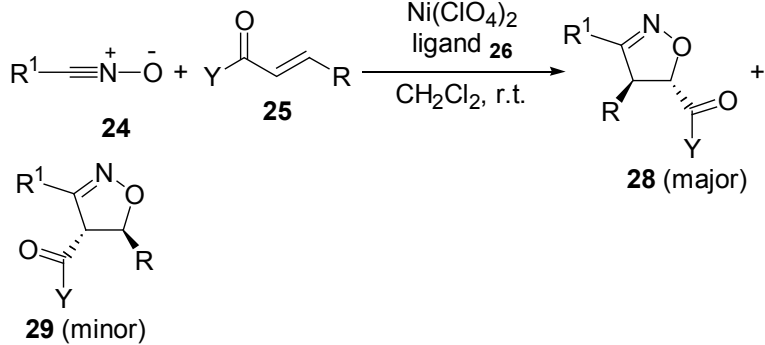

$$
\mathrm{R}^{1}=2,4,6-\mathrm{Me}_{3} \mathrm{C}_{6} \mathrm{H}_{2}
$$<smiles>CC1(C)CN([Y]N=[W])C(=O)O1</smiles><smiles></smiles>

26

2009 年, Suga 等 ${ }^{[14]}$ 改用 $(R)-B I N I M-2 Q N$ (27a)替代 双噁唑啉配体 26 (Scheme 3), 探讨了氧化腈 24 与活泼 烯烃 25 的环加成反应(Eq. 7). 研究发现：与氧化腈进行 环加成反应，吡唑烷酮得到的对映选择性和区域选择性 普遍比噁唑烷酮高. 并且芳香族氧化腈和脂肪族氧化腈 均可与啞唑烷酮和吡唑烷酮发生成环反应，实验结果比 较令人满意 $($ 表 3$)$.

表 3 底物 24 和 25 中不同取代基对环加成反应的影响

Table 3 Effect of different substituents of substrates $\mathbf{2 4}$ and $\mathbf{2 5}$ on cycloaddition reactions

\begin{tabular}{|c|c|c|c|c|c|}
\hline Entry & $\mathrm{R}^{1}$ & 25 & Yield $/ \%$ & $d r$ & $e e / \%$ \\
\hline 1 & $\mathrm{Ph}$ & $25 a$ & 94 & $99: 1$ & 95 \\
\hline 2 & $p-\mathrm{MeOC}_{6} \mathrm{H}_{4}$ & 25a & 97 & $99: 1$ & 92 \\
\hline 3 & $i$-Bu & $25 a$ & 99 & $99: 1$ & 87 \\
\hline 4 & $\mathrm{Ph}$ & $25 b$ & 74 & $96: 4$ & 89 \\
\hline 5 & $p-\mathrm{MeOC}_{6} \mathrm{H}_{4}$ & $25 b$ & 84 & $88: 12$ & 83 \\
\hline 6 & $i-\mathrm{Bu}$ & $25 b$ & 82 & $93: 7$ & 72 \\
\hline
\end{tabular}

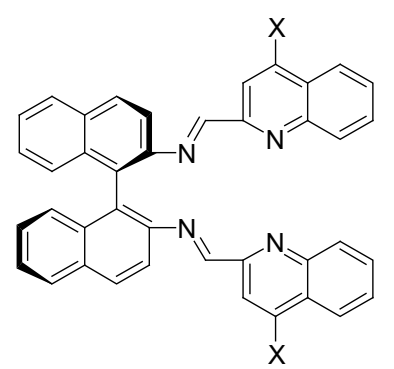

27a: $(R)-\mathrm{BINIM}-2 \mathrm{QN}(\mathrm{X}=\mathrm{H})$

27b: $(R)$-BINIM-4Me-2QN $(\mathrm{X}=\mathrm{Me})$

27c: $(R)-\mathrm{BINIM}-4 \mathrm{Ph}-2 \mathrm{QN}(\mathrm{X}=\mathrm{Ph})$

Scheme 3

\section{4 其他 1,3-偶极体参与的[3+2]环加成}

此外, 有关镍催化其他 1,3-偶极环加成反应也有少 量报道. Suga 等 ${ }^{[15]}$ 在 2007 年报道了 $(R)$-BINIM-4Me- 
2QN (27b)-Ni(II)配合物催化甲亚胺 30 与噁唑烷酮 25c 发生偶极-HOMO/亲偶极-LUMO 控制的环加成反应, 得到 trans 构型吡唑烷骨架结构 31 (Eq. 8). 作者认为 $\mathrm{C}=\mathrm{O}$ 对 $\mathrm{C}=\mathrm{C}$ 的共轭拉电子效应, 致使环加成反应以 偶极-HOMO/亲偶极-LUMO 控制方式进行.
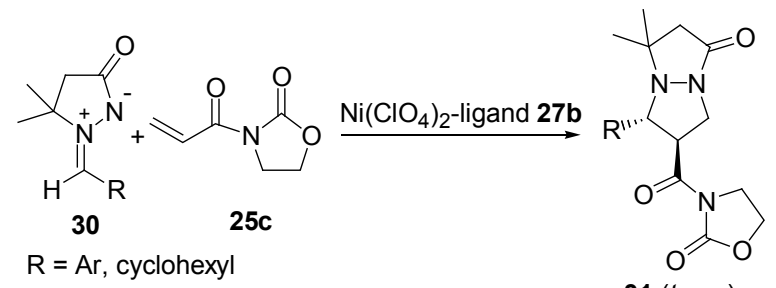

31 (trans) $74 \% \sim 97 \%$ ee

同年，Suga 等 ${ }^{[16]}$ 又报道了 $\mathbf{2 7 b}-\mathrm{Ni}(\mathrm{II})$ 配合物催化羰 基叶立德 33 与乙烯基醚发生反电子需求的偶极体$\mathrm{LUMO}$ /亲偶极体-HOMO 控制的环加成反应, 得到 endo 构型产物 34 (Scheme 4). 作者认为可能是由于乙烯基醚 中的氧原子与 $\mathrm{C}=\mathrm{C}$ 键发生 $\mathrm{p}-\pi$ 共轭, 增加 $\mathrm{C}=\mathrm{C}$ 键的电 子云密度, 致使成环反应以偶极 $-\mathrm{HOMO} /$ 亲偶极 LUMO 控制方式进行. 最近, 该研究小组 ${ }^{[17]}$ 报道了 (R)-BINIM-4Ph-2QN (27c)-Ni(II)配合物催化重氮酯 35 与吡唑烷酮 25d 发生环加成反应, 得到吡唑啉环结构 (36) (Eq. 9).

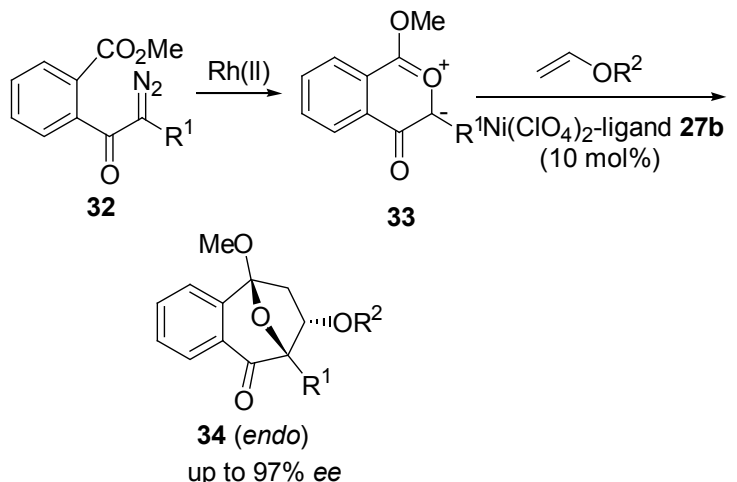

$\mathrm{R}^{1}=\mathrm{H}, \mathrm{COPr}, \mathrm{COPr}-i, \mathrm{COBu}, \mathrm{COBu}-i, \mathrm{CO}-c-\mathrm{Hex}, \mathrm{COBn}$, etc. $\mathrm{R}^{2}=c-\mathrm{Hex}$

\section{Scheme 4}

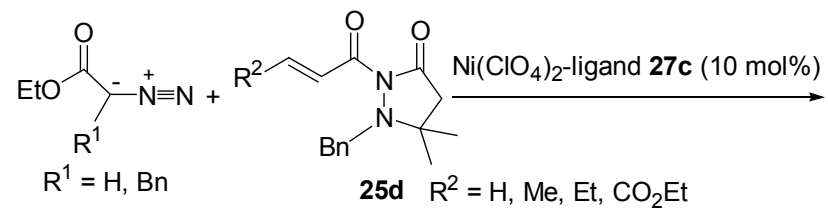
35<smiles>[R16]C1C(C(=O)OCC)=NNC1C(=O)N1C(=O)CC(C)(C)N1Cc1ccccc1</smiles>

\section{5 (杂)环丙烷参与的[3+2]环加成}

早在 1985 年, Binger 等 ${ }^{[18]}$ 就报道了 $\mathrm{Ni}(\mathrm{COD})_{2}$-单膦 配体 TOPP 配合物催化三甲基硅烷基炔烃 37a 与亚甲基 环丙烷 38 发生 $[3+2]$ 环加成反应, 得到环戊烯衍生物 39a 39c (Eq. 10). 2011 年, Ogoshi 等 ${ }^{[19]}$ 报道了镍催化环 丙基酮 40 与中间炔烃 37 的成环反应(Eq. 11). 研究发现, 添加剂 $\left(\mathrm{CH}_{3}\right)_{2} \mathrm{AlCl}$ 对此环加成反应不可或缺. 值得注意 的是，含酯基、醚基和羰基等活性基团的炔烃不能发生 环加成反应，可能是由于 $\left(\mathrm{CH}_{3}\right)_{2} \mathrm{AlCl}$ 与此类活性炔烃中 的氧配位而使其活性降低.
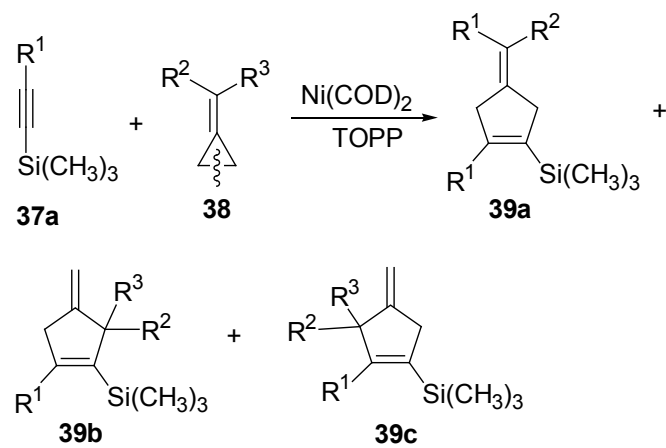

$\mathrm{COD}=1,5$-cyclooctadiene, $\mathrm{TOPP}=$ triarylphosphite

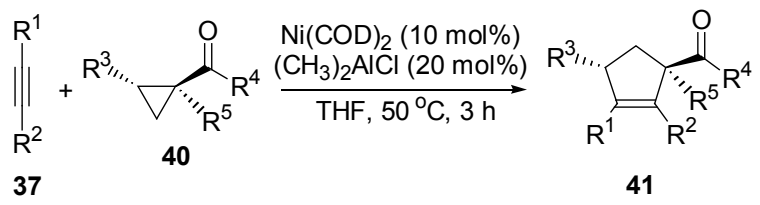

同年，浙江大学张玉红等 ${ }^{[20]}$ 实现了镍催化亚甲基 环丙烷一炔烃化合物 42 的分子内 $[3+2]$ 环加成, 反应通 过邻位 $\mathrm{C}-\mathrm{C}$ 键的断裂生成环戊 $[a]$ 狮衍生物 43 (Eq. 12).

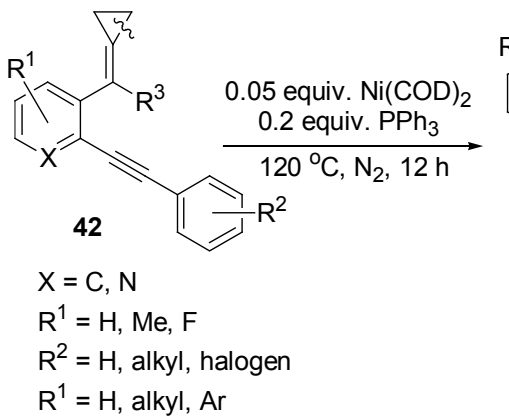

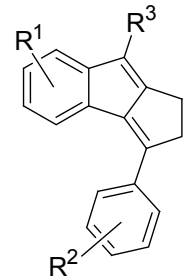

43

up to $84 \%$ yield
最近，华东师范大学张俊良等 ${ }^{[21]}$ 跟踪了氮杂环丙 烷 44 与芳香醛 45 在镍催化作用下通过 $\mathrm{C}-\mathrm{C}$ 键断裂发 生[3+2]环加成反应, 得到多取代 1,3-啞唑烷衍生物 46 (Eq. 13). 之后，张俊良等 ${ }^{[22]}$ 又报道了镍催化环氧乙烷 基二酮/二酸酯 $\mathbf{4 7}$ 与吲哚 48 发生分子间 [3+2]成环反应, 合成呋喃[3,4-b]吲哚衍生物 49 (Eq. 14). 

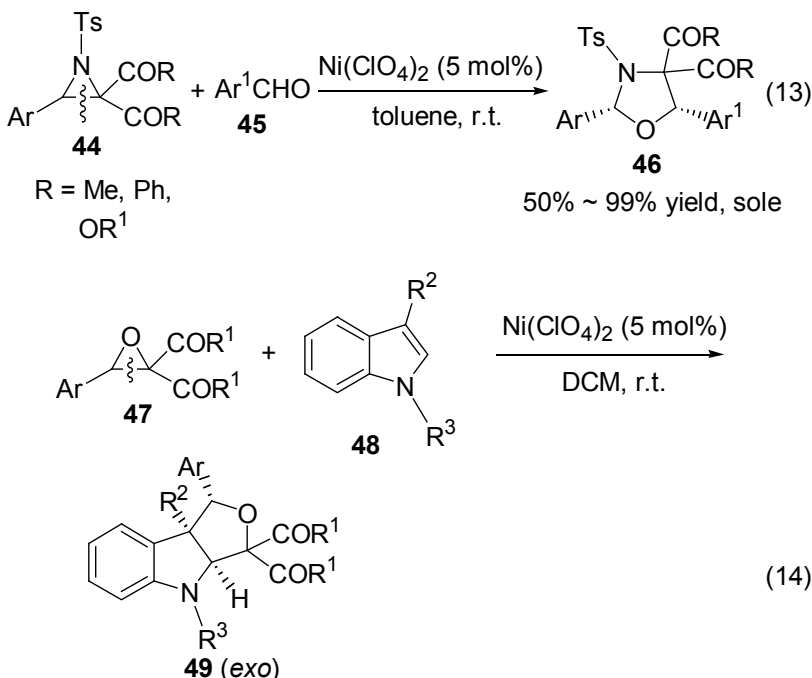

\section{2 [2+2+2]环加成}

过渡金属催化烯、炔等不饱和基团的 $[2+2+2]$ 环加 成是合成六元环状化合物最直接、原子利用率最高的方 法, 此类反应已成为当前研究的热点. 关于过渡金属催 化乙炔进行 $[2+2+2]$ 环加成反应的最早是 Reppe 等 ${ }^{[23]}$ 在 1948 年用镍配合物作催化剂实现的. 之后, Volihardt 等 ${ }^{[24]}$ 首次把钴催化 $[2+2+2]$ 环加成成功应用于合成天 然产物苯并环丁烯.

\section{1 单炔-异氰酸酯的分子间 $[2+2+2]$ 环加成}

2005 年, Louie 等 ${ }^{[25]}$ 在研究镍催化炔烃与异氰酸酯 进行 $[2+2+2]$ 环加成反应时, 发现底物浓度和配体体 积对环加成产物的影响很大. 实验结果表明: 当用大体 积配体 IPr 时, 一分子炔烃与两分子异氰酸酯反应得到 $1: 2$ 组合产物 51; 当用小体积配体 $\mathrm{PEt}_{3}$ 替换 $\mathrm{IPr}$ 时, 两 分子炔烃与一分子异氧酸酯反应得到 $2: 1$ 组合产物 52 (Scheme 5).

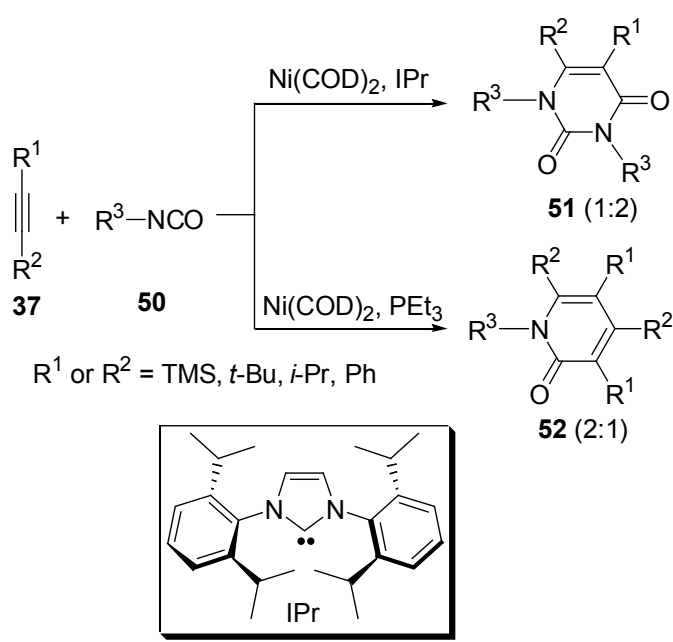

Scheme 5

\section{2 苯炔-单烯-单炔的分子间 $[2+2+2]$ 环加成}

2009 年, 香港中文大学谢作伟等 ${ }^{[26]}$ 跟踪了镍/钯催 化苯炔(前体 53)、活泼单烯 54 和单炔 37 进行 $[2+2+2]$ 环加成反应(Eq. 15). 实验发现: $\mathrm{Ni}(\mathrm{COD})_{2}$ 能有效催化芳 炔一烯烃-炔烃三组分成环得到二氢化荎骨架 55 . 但令 人不解的是, 钯配合物如 $\mathrm{PdCl}_{2}\left(\mathrm{PPh}_{3}\right)_{2}$ 和 $\mathrm{Pd}\left(\mathrm{PPh}_{3}\right)_{4}$ 均不 能有效催化三组分 $[2+2+2]$ 环加成, 不过在产物中检 测到二组分苯炔一烯一苯炔环加成产物 56 和交叉偶联产 物 57.

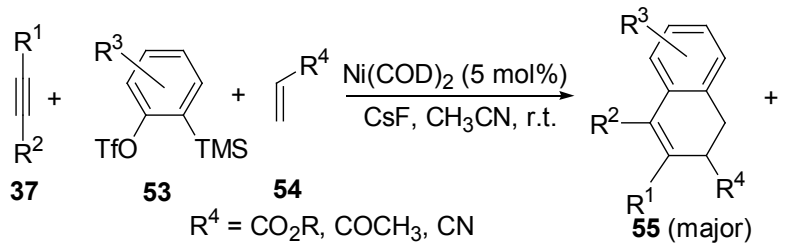<smiles>[R][R]1ccc2c(c1)CC([R])C1=C2[14CH]=[R][R]C=C1</smiles><smiles>[R]C=Cc1cc[R](F)cc1-c1ccc([R])cc1</smiles>

反应机理如 Scheme 6 所示，首先苯炔、烯丙酸与 $\mathrm{Ni}(0)$ 配合物氧化偶联形成五元镍环中间体 $\mathbf{5 8}$, 活泼烯 烃中氧的孤对电子与镍的空 $\mathrm{d}$ 轨道配位有助于该中间体 的稳定; 随后极化炔烃插入 $\mathrm{Ni}-\mathrm{C}_{\text {aryl }}$ 键得到七元镍环中 间体 59; 再通过还原消除得到最终产物二氢化萗衍生 物 55a.

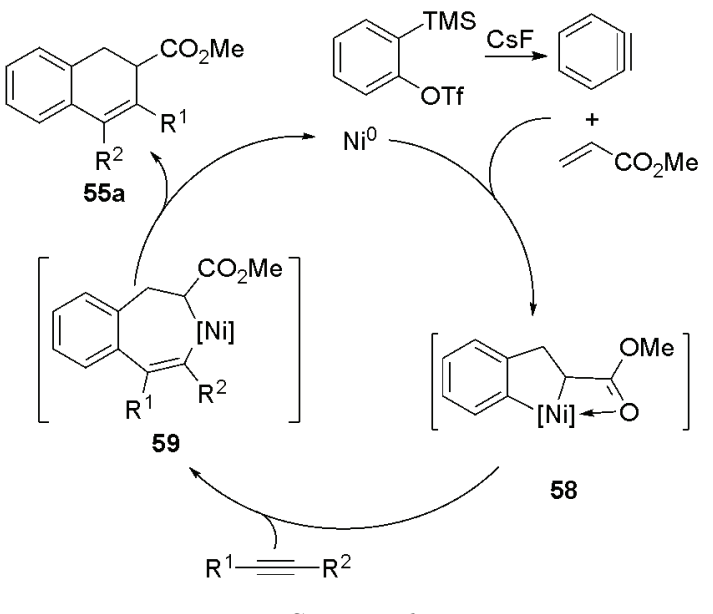

Scheme 6

\section{3 碳硼炔-单炔-单炔(烯)三组分 $[2+2+2]$ 环加成}

(邻)碳硼烷 60 于 1963 年首次被 Heying 等 ${ }^{[27]}$ 发现. 10 年后, Sayler 等 ${ }^{[28]}$ 合成了首个金属一碳硼炔配合物 $\left[\eta^{2}-\mathrm{C}_{2} \mathrm{~B}_{10} \mathrm{H}_{10} \mathrm{Ni}\left(\mathrm{PPh}_{3}\right)\right](\mathbf{6 1}) .2006$ 年，谢作伟等 ${ }^{[29]}$ 首次利 用此配合物与两分子中间炔烃进行 $[2+2+2]$ 环加成反 应，得到 1,2-苯并邻碳硼烷衍生物 62 (Scheme 7). 由于 碳硼烷空间位阻大，不对称炔烃可以实现高区域选择性 
环加成, 且空间位阻小的炔烃得到的产率更高. 值得注 意的是, 末端炔烃易使镍一碳砳炔配合物 61 质子化而难 以发生此类反应，且含酯基的炔烃在 $\mathrm{Ni}(0)$ 作用下更倾 向于自身三聚 ${ }^{[30]} .2010$ 年, 谢祚伟等 ${ }^{[31]}$ 又以 1-碘-2-锂碳 硼烷作为碳硼炔前体, 在相同条件下与炔烃反应亦得到 产物 62 .

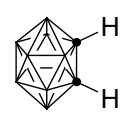

60

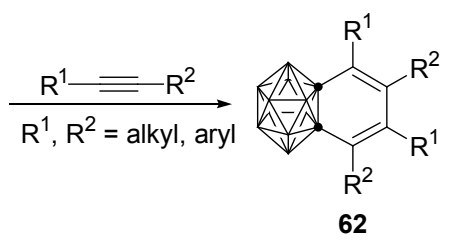

$33 \% \sim 67 \%$ yield

\section{Scheme 7}

最近，谢作伟等 ${ }^{[32]}$ 尝试用两种不同炔烃与 61 反应. 但由于金属对两种不同炔烃缺乏选择性，反应得到混合 物. 加入 $\mathrm{Cp}_{2} \mathrm{Zr}(\mu-\mathrm{Cl})\left(\mu-\mathrm{C}_{2} \mathrm{~B}_{10} \mathrm{H}_{10}\right) \mathrm{Li}\left(\mathrm{OEt}_{2}\right)_{2}(\mathbf{6 3})$ 作辅助 剂, 成功实现了镍催化碳嗍炔与两种不同炔烃的 $[2+$ $2+2$ ]成环反应.

根据研究结果, 谢作伟等提出了可能的反应机理 (Scheme 8): 其中最关键的一步是五元锆环 64 的生成, 随后发生过渡金属化转化成五元镍环中间体 $\mathbf{6 5}$, 另一 种炔烃插入形成七元镍环中间体 66 , 最后还原消除得 到 1,2-苯并邻碳硼烷衍生物 67.

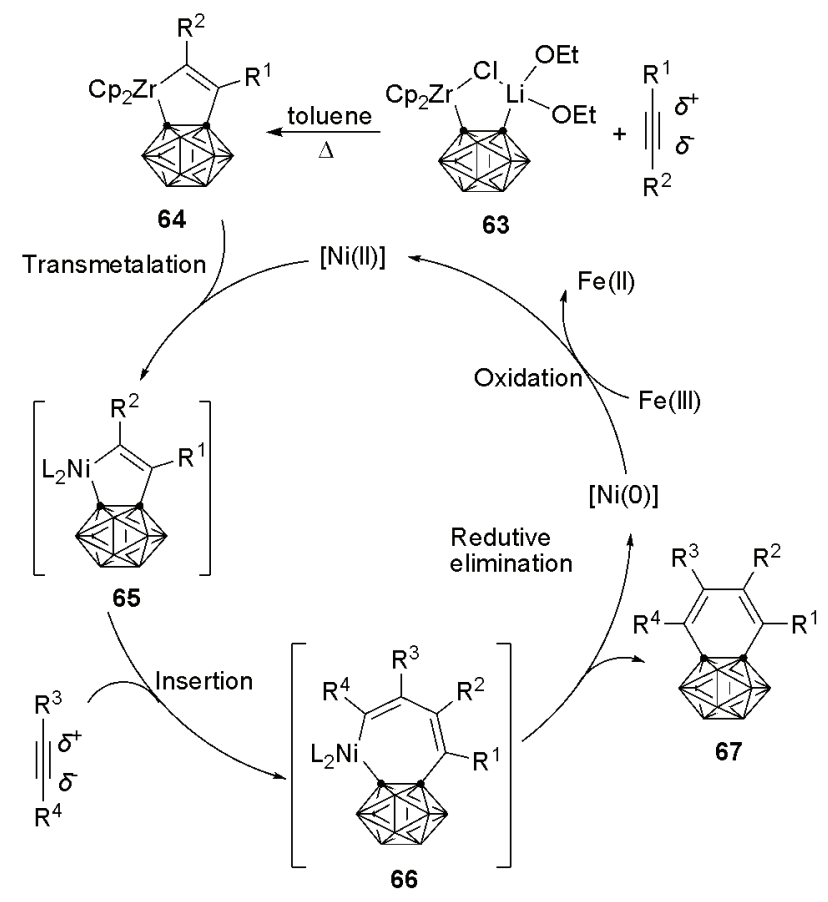

Scheme 8
2008 年，谢作伟等 ${ }^{[33]}$ 报道了 $\mathrm{NiCl}_{2}\left(\mathrm{PPh}_{3}\right)_{2}$ 催化碳硼 炔与一般烯烃进行反应, 实验中检测到 $\mathrm{C}-\mathrm{C}$ 偶联产物 68 或 69 的生成. 将一般烯烃改成活泼烯烃, 则得到烷 基碳嗍烷衍生物 70 (Scheme 9). 他们认为活泼烯烃较易 插入 61 形成五元镍环中间体 71, 这是由于活泼烯烃中 杂原子(氮或氧)上的孤对电子可与镍的空 $\mathrm{d}$ 轨道配位而 有利于中间体 71 的稳定. 另一分子烯烃不能再插入此 五元镍环中间体进行反应，不过研究发现炔烃却能顺利 插入得到七元镍环中间体 $\mathbf{7 2}$, 再经历还原消除最终得 到二氢苯并碳硼烷衍生物 73 (Scheme 10) ${ }^{[34]}$.

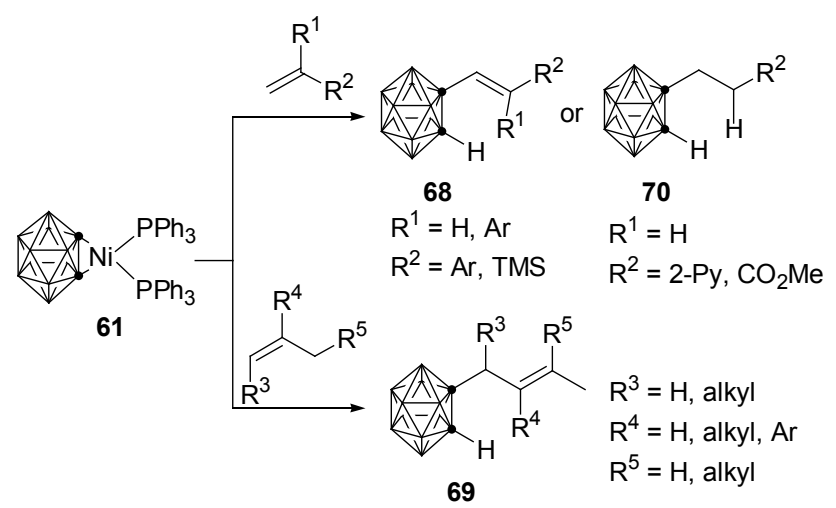

\section{Scheme 9}

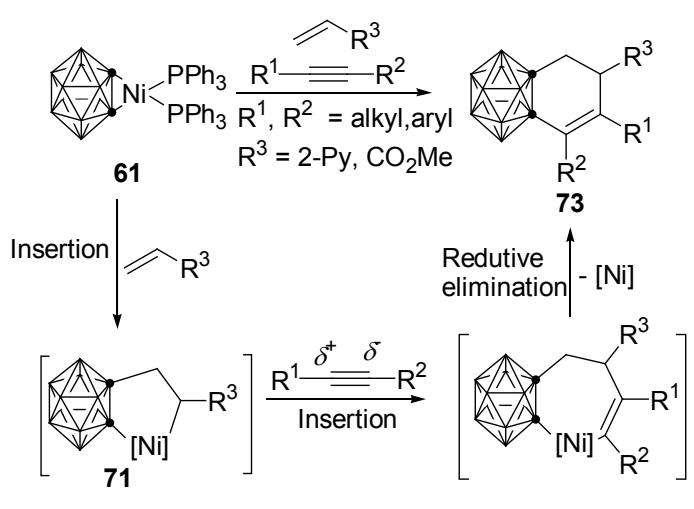

72

Scheme 10

\section{4 二炔与 $\mathrm{CO}_{2}$ 的分子间 $[2+2+2]$ 环加成}

早在 1988 年, Tsuda 等 ${ }^{[35]}$ 就报道用 $\mathrm{Ni}(\mathrm{COD})_{2}$-单膦 配体 $\mathrm{PR}_{3}$ ( $\mathrm{R}$ 为烷基)催化末端二烷基取代二炔与 $\mathrm{CO}_{2}$ 进 行 [2+2+2]环加成得到中等产率的双环 $\alpha$-吡喃酮. 近 年来, 新型大位阻、富电子烷基氮杂环卡宾( $\mathrm{NHC}$ )配体 的出现及其在不对称催化反应中的应用引起研究者们 的极大兴趣 ${ }^{[36]} .2002$ 年, Louie 等 ${ }^{\left[{ }^{[3]}\right.}$ 用 NHC 配体 IPr 替 换 $\mathrm{PR}_{3}$, 与 $\mathrm{Ni}(\mathrm{COD})_{2}$ 组成的催化体系催化对称二炔与 $\mathrm{CO}_{2}$ 进行 $[2+2+2]$ 环加成反应(Eq. 16), 产率高达 $97 \%$. 接下来 Louie 等 ${ }^{[38]}$ 尝试了不对称二炔与 $\mathrm{CO}_{2}$ 的成环反 应，主要得到产物 77 (Eq. 17). 

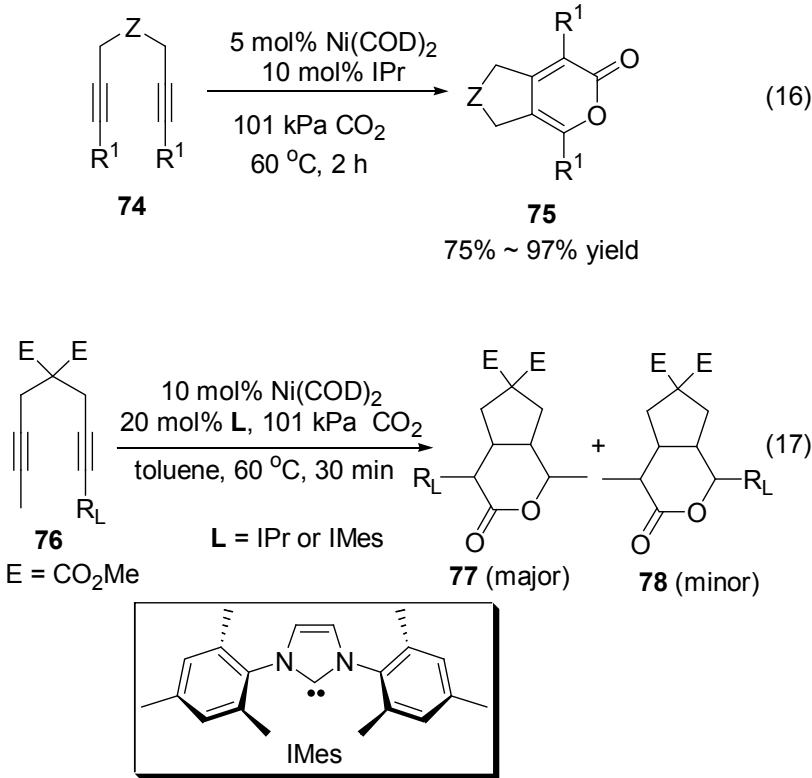

\section{5 二炔与腈的分子间 $[2+2+2]$ 环加成}

2005 年, Louie 等 ${ }^{[39]}$ 改用腈替换 $\mathrm{CO}_{2}$, 以 $\mathrm{NHC}$ 配体 SIPr 作手性配体, 镍催化作用下与二炔进行 $[2+2+2]$ 环加成反应, 可以合成天然产物和药物中常见的吡啶环 骨架结构 80. 值得一提的是, 位阻大的腈、芳香腈也可 与含杂原子的二炔进行此类反应, 且产率较理想. 不过 $\mathrm{NHC}$ 配体对空气敏感, 给实际操作过程带来不便. 为此 Louie 等 ${ }^{[40]}$ 用对空气较稳定的 NHC 配体盐酸盐作前体, 在强碱 $n-\mathrm{BuLi}$ 作用下转化成实际起催化作用的 $\mathrm{Ni}(0) / \mathrm{NHC}$ 配体催化体系(Scheme 11), 获得了较好的实 验结果. 但将 $\mathrm{NHC}$ 配体盐酸盐应用于二炔与 $\mathrm{CO}_{2}$ 、醛 或异氧酸酯的 $[2+2+2]$ 环加成反应时, 实验结果都不 太理想。

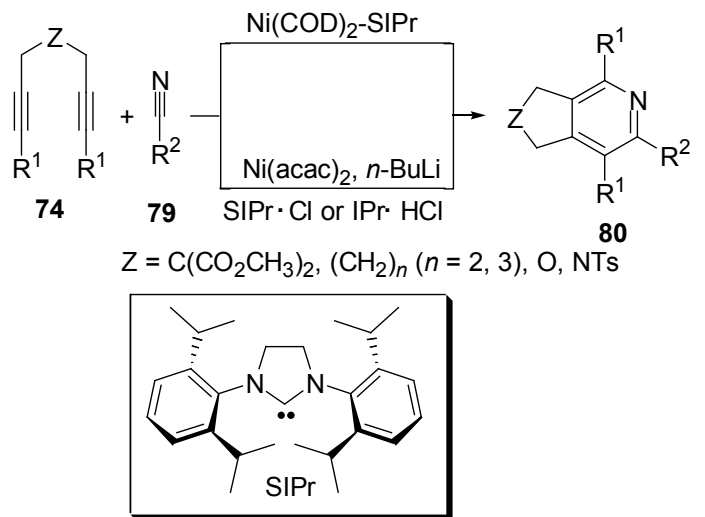

Scheme 11

\section{6 二炔与醛的分子间 $[2+2+2]$ 环加成}

早在 1988 年, Tsuda 等 ${ }^{[41]}$ 报道过 $\mathrm{Ni}(\mathrm{COD})_{2}-\mathrm{PR}_{3}(\mathrm{R}$ 为烷基或苯基)催化二炔与醛进行 $[2+2+2]$ 环加成反应
得到 $\alpha$-吡喃环，同时在产物中也检测到二烯酮衍生物 (即 $\alpha$-吡喃环的开环产物), 有时甚至是主要产物. 这一 实验结果启发我们用过渡金属催化二炔与醛进行成环 反应可以合成二烯酮衍生物. 2005 年, Louie 等 ${ }^{[42]}$ 改用 $\mathrm{SIPr}$ 替换 $\mathrm{PR}_{3}$ ，与 $\mathrm{Ni}(\mathrm{COD})_{2}$ 形成催化体系催化对称二炔 与醛进行环加成反应，主要获得二烯酮衍生物 82 (Scheme 12). 实验结果表明: 连有供电子基团的苯甲醛 得到的产率较连有吸电子基团的苯甲醛高，且脂肪醛也 可以转化成相应的产物(表 4).

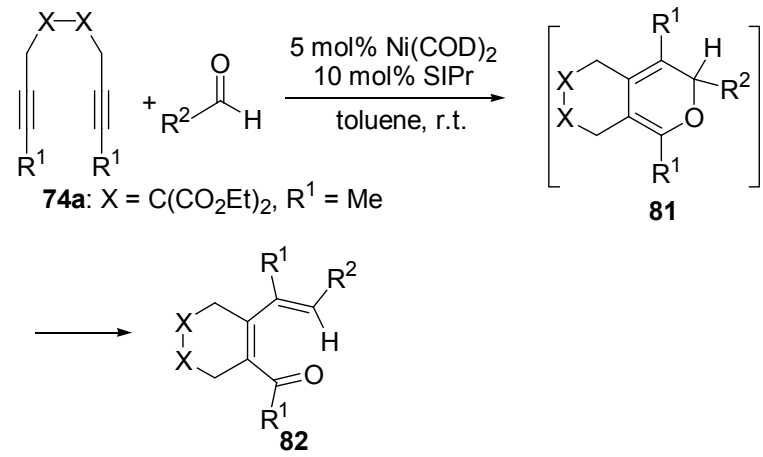

Scheme 12

表 4 醛取代基对环加成反应的影响

Table 4 Effect of substituents of aldehydes on cycloaddition reactions

\begin{tabular}{ccc}
\hline Entry & $\mathrm{R}^{2}$ & Yield/\% \\
\hline 1 & $\mathrm{Ph}$ & 78 \\
2 & $p-\mathrm{MeOC}_{6} \mathrm{H}_{4}$ & 91 \\
3 & $p-\mathrm{CF}_{3} \mathrm{C}_{6} \mathrm{H}_{4}$ & 65 \\
4 & $n-\mathrm{Pr}$ & 58 \\
5 & $i-\mathrm{Pr}$ & 72 \\
\hline
\end{tabular}

\section{7 二炔与烯酮的分子间 $[2+2+2]$ 环加成}

2011 年, Louie 等 ${ }^{[43]}$ 报道了 $\mathrm{Ni}(\mathrm{COD})_{2}$-双膦配体 DPPB 配合物催化二炔与烯酩进行 $[2+2+2]$ 环加成反应 (Eq. 18). 尽管烯酮有两个反应部位，但实验结果中并未 检测到羰基反应的成环产物，仅生成环已二烯酮环产物 83. 研究结果表明: 底物烯酮芳基对位上连有拉电子基 团有利于产物的形成，连有供电子取代基则不利

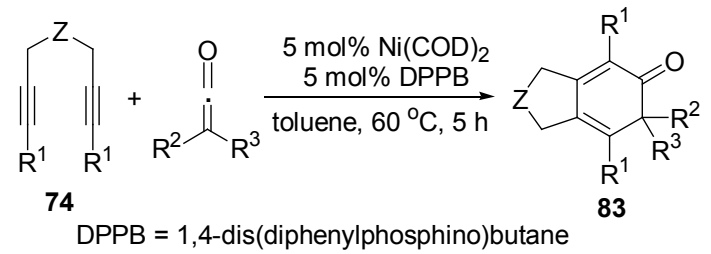

\section{3 [4+2]环加成}

\subsection{1,3-氮杂二烯-乙烯醚的 $[4+2]$ 环加成}

2007 年, Carretero 等 ${ }^{[44]}$ 用由 $\mathrm{Ni}\left(\mathrm{ClO}_{4}\right)_{2}$ 和 $\mathrm{DBFOX}-\mathrm{Ph}$ 
制得的手性镍配合物高对映选择性地催化氮杂 1,3-二烯 84 与乙烯基醚进行反电子需求的 Diels-Alder 反应, 得 到 endo 构型产物 85 (Eq. 19). 作者认为, 亚胺氮上磺酰 基的强拉电子效应和乙烯基醚中烷氧基的强供电子作 用，致使反应以反电子需求 Diels-Alder 加成方式进行.
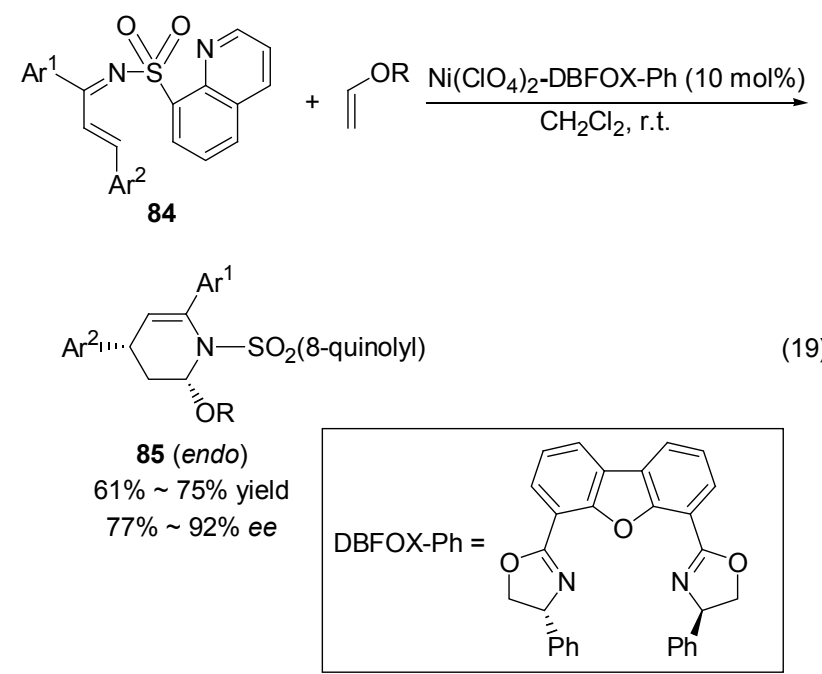

\subsection{1,3-二烯-腈的[4+2]环加成}

过渡金属催化两分子炔烃与一分子腈的 $[2+2+2]$ 环加成反应是合成吡啶环骨架非常直接、有效的方 法 $^{[45]}$, 但这种途径区域选择性差, 在吡定环化合物的合 成中受到一定的限制. 最近, Ogoshi 等 ${ }^{[46]}$ 用 $\mathrm{Ni}(\mathrm{COD})_{2}-$ $\mathrm{PCy}_{3}$ 催化 1,3-二烯 86 与腈经过[4+2]脱氢环加成反应, 得到单一的 5 位未取代的吡啶单环化合物 87 (Eq. 20), 该反应具有高度的区域选择性. 值得一提的是, 利用此 方法可以合成二个甚至三个吡定单环结构的化合物, 且 产率均在 $65 \%$ 以上.

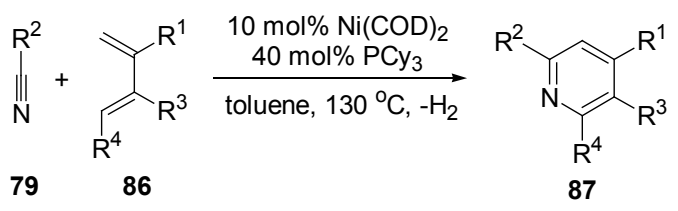

反应机理如 Scheme 13 所示, 腈、二烯与 $\mathrm{Ni}(0)$ 配 合物氧化环化形成 $\eta^{3}$-氮烯丙基镍环中间体 $\mathbf{8 8}$, 异构化 得到较稳定的中间体 89,89 能可逆地与腈结合形成 $\mathbf{9 0}$, 亦能依次经历还原消除、脱氢最终得到吡定衍生物 $87 \mathrm{a}$.

\section{3 酰胺一炔的 $[4+2]$ 环加成}

Nokao 等 ${ }^{[47]}$ 用 $\mathrm{Ni} / \mathrm{Al}\left(\mathrm{CH}_{3}\right)_{3}$ 联合催化活化甲酰胺 91 中的两个 $\mathrm{C}-\mathrm{H}$ 键, 与中间炔烃进行 $[4+2]$ 成环反应, 得 到二氢吡啶酮环产物 92 (Eq. 21). 反应对不对称炔烃有 较好的区域选择性, 炔烃上较小取代基连在羰基 $\alpha$-位即 为主要产物.

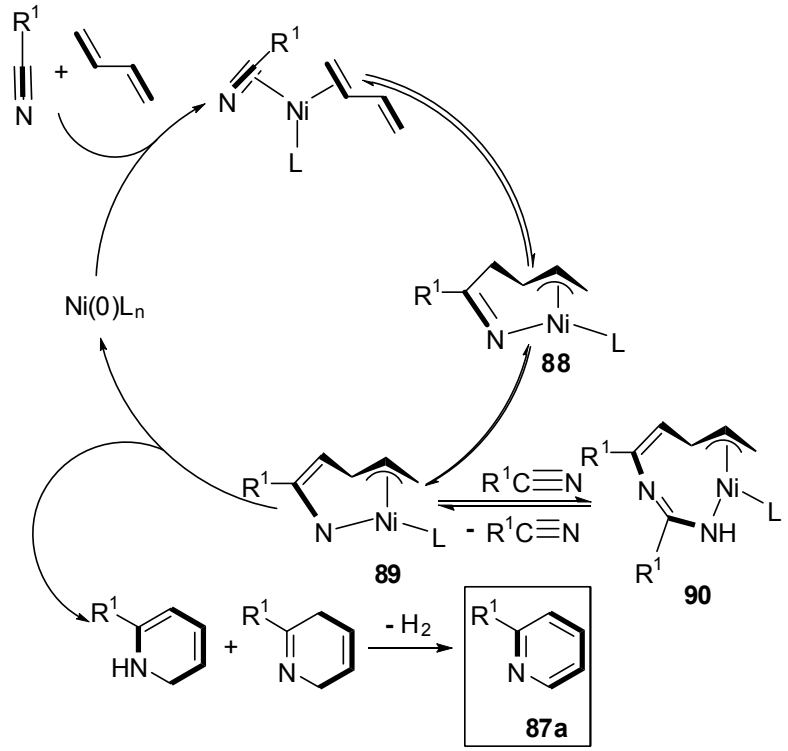

Scheme 13

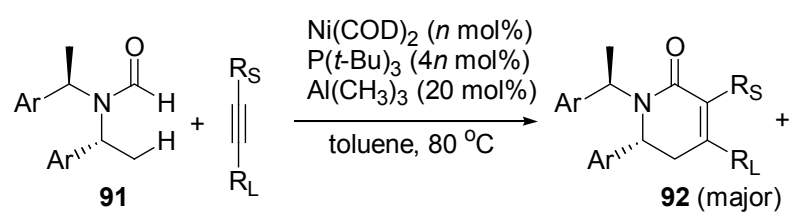<smiles>[R]C1=C([R])C(=O)N(C(C)[Al])[C@H]([AlH2])C1</smiles>

93 (minor)

\section{$4[4+2+2]$ 环加成}

\section{1 环丁酮-二炔的 $[4+2+2]$ 环加成反应}

2006 年, Murakami 等 ${ }^{[48]}$ 发现镍配合物可有效催化 环丁酮 94 通过 $\mathrm{C}-\mathrm{C}$ 键断裂与二炔进行 $[4+2+2]$ 成环 反应，得到环辛二烯酮衍生物 95 (Eq. 22). Murakami 等 [49]在 2008 年再一次报道了镍催化环丁酮与二炔的成环 反应，所得结果与 2006 年报道的结果一致.

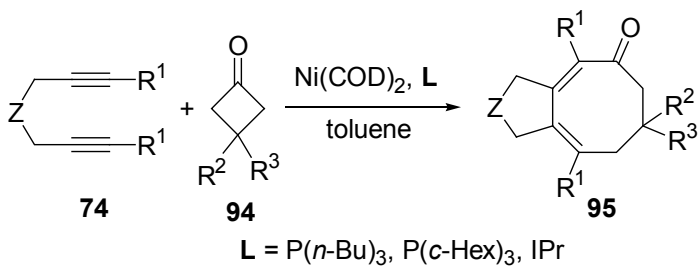

\section{2 氮杂环丁酮 - 二炔的 $[4+2+2]$ 环加成反应}

最近, Louie 等 ${ }^{[50]}$ 报道了 $\mathrm{Ni}(\mathrm{COD})_{2}$-IPr 高区域选择 性地催化氮杂环丁酮 96 与二炔发生 $[4+2+2]$ 环加成反 应得到氮杂环辛二烯酮化合物 97 (Eq. 23). 值得一提的 是，含各种官能团(甚至包括磺酰基、氧基)的二炔均可 以发生此类反应，且产率高达 $91 \%$. 

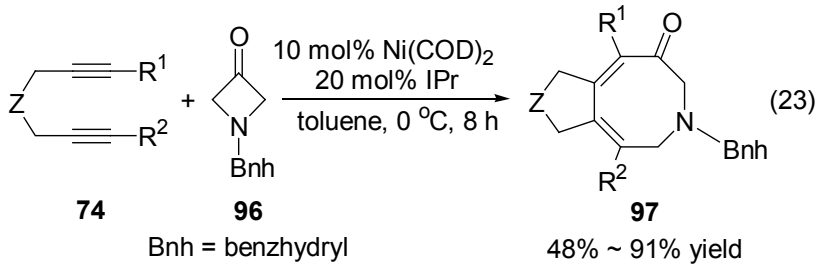

\section{$5 \quad[3+2+2]$ 环加成}

2004 年, Saito 等 ${ }^{[51]}$ 用 $\mathrm{Ni}(\mathrm{COD})_{2}-\mathrm{PPh}_{3}$ 催化亚环丙基 乙酸乙酯 $(\mathbf{9 8})$ 与两分子末端炔烃进行 $[3+2+2]$ 成环反 应, 主要得到 $E$ 型环庚二烯衍生物 99. 随后以 $\mathrm{Ni}(\mathrm{COD})_{2}-\mathrm{PR}_{3}$ 作催化剂, 用二炔替换炔烃反应通常得 到 $E / Z$ 构型混合的双环化合物 $\mathbf{1 0 0}$ (Scheme 14) ${ }^{[52]}$.

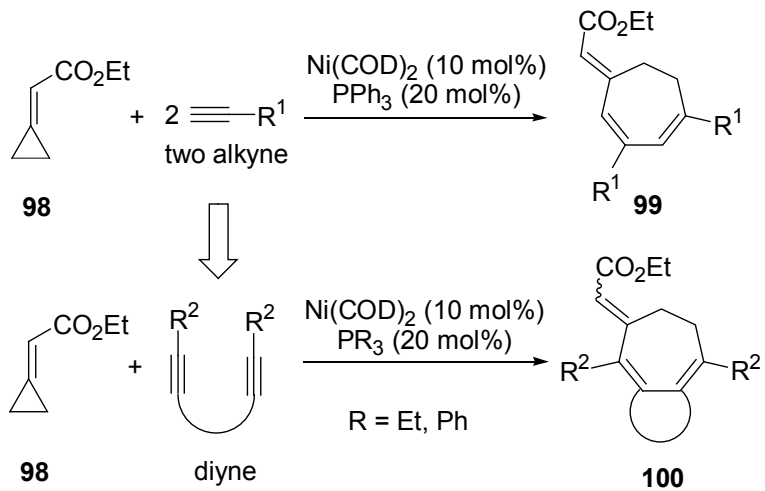

Scheme 14

2009 年, Saito 等 ${ }^{[53]}$ 研究了 $\mathrm{Ni}(\mathrm{COD})_{2}-\mathrm{PPh}_{3}$ 催化 98、

1,3-二炔与末端单炔的成环情况. 研究发现: 当加入 3 equiv. 1,3-二炔与 98 反应，得到 $2: 1$ 联合环化产物 101; 当加入等量(1.5 equiv.)的 1,3-二炔和末端单炔与 98 反 应, 得到 $1: 1: 1$ 联合环化产物 102 (Scheme 15). 这表 明在末端炔烃较 1,3-二炔活泼。

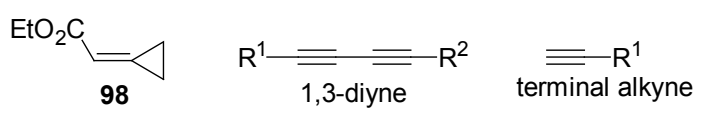

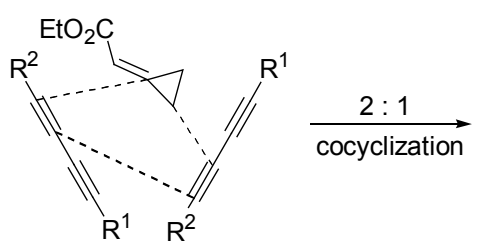<smiles>[R]C#CC1=C([R])C(C#C[R])=C([R])C(C(=O)OCC)=CC1</smiles>

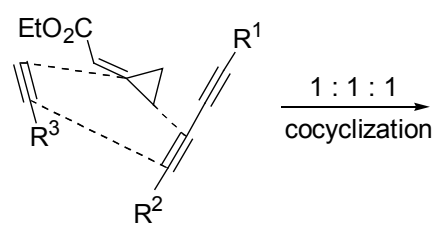<smiles>[R]C#CC1=C([R20])C([R20])=CC(=CC(=O)OCC)C1</smiles>

\section{6 其他类型的环加成反应}

近年来关于镍催化环加成反应还有少量其他反应 类型. Moretó 等 ${ }^{[54]}$ 在 2005 年报道了镍催化炔烃、烯丙基 卤化物 103 与 $\mathrm{CO}$ 发生 Pauson-Khand 型反应得到产率较 高的环戊烯酮衍生物 104 (Eq. 24). Wender 等 ${ }^{[55]}$ 在 2009 年报道了(DME) $\mathrm{NiBr}_{2}$ 催化 1,6-二炔通过自身 $[2+2+$ $2+2]$ 环加成合成六/八取代环辛四烯衍生物 105 (Eq. 25). Saito 等 ${ }^{[56]}$ 在 2010 年报道了 $\mathrm{Ni}\left(\mathrm{PPh}_{3}\right)_{2}$ 催化 98 与二 烯炔 106 进行 $[4+3+2$ ]环加成得到九元环化合物 107 和 108 (Eq. 26). 最近 Ogoshi 等 ${ }^{[57]}$ 报道了镍配合物高区域 选择性催化 $\alpha, \beta$-不饱和烯烃 109 与共轭烯炔 110 发生分 子间 $[2+2]$ 环加成(Eq. 27), 反应经过重要中间体 111, 再通过还原消除得到环丁烯衍生物 112a (Scheme 17).
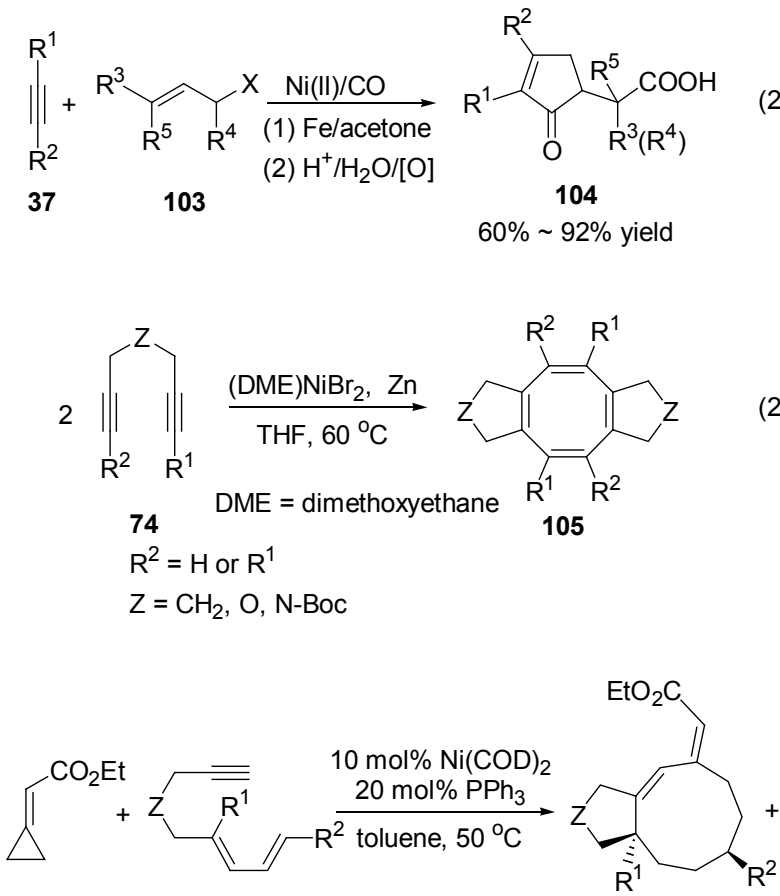

98

106 107 $\mathrm{Z}=\mathrm{O}, \mathrm{NTs}, \mathrm{C}\left(\mathrm{CO}_{2} \mathrm{Et}\right)_{2}$

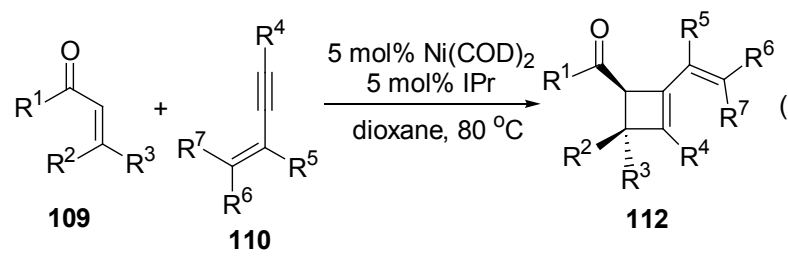




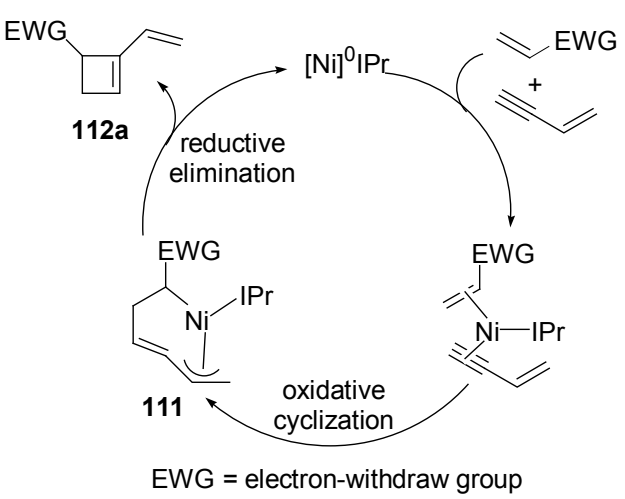

Scheme 17

\section{7 结论与展望}

环加成反应是合成单环及多环化合物一类非常直 接、有效的方法, 过渡金属催化剂应用于环加成反应是 有机化学研究的热点之一. 镍催化 $[3+2],[2+2+2]$, $[4+2],[4+2+2],[3+2+2]$ 等环加成反应的研究为有 机合成提供了更多的方法和手段, 实现了许多由直链化 合物向环状化合物的转化, 并且使得此类反应可在较温 和的条件下进行. 特别是在 $[3+2]$ 和 $[2+2+2]$ 环加成反 应中, 镍催化显示出较好的催化活性和良好的选择性. 但相比于其他过渡金属催化的环加成反应, 镍催化应用 的范围还是较小, 催化剂的用量也相对较多. 因此, 发 展高催化活性、高对映选择性的镍配合物催化体系及其 在其他类型的环加成反应中的应用仍然是将来需要研 究的重点课题之一.

\section{References}

[1] Diels, O.; Alder, K. Justus Liebigs Ann. Chem. 1928, 460, 98.

[2] Bai, G.-Y.; Chen, L.-G.; Li, Y.; Cao, L.; Song, C.-J.; Wang, F.-L. J. Tianjin Univ. 2002, 35, 332 (in Chinese). (白国义, 陈立功, 李阳, 曹琳, 宋传君, 王丰雷, 天津大学学报, 2002, 35, 332.)

[3] Chen, C.-S.; Li, Z.-N.; Su, J.-Y.; Li, T.; Zhang, B.-Y. Chin. J. Org. Chem. 2005, 25, 1392 (in Chinese).

(程春生, 李志念, 苏金燕, 李涛, 张宝砚, 有机化学, 2005, 25, 1392.)

[4] Xu, X.-X.; Wei, Z.-L.; Bai, X. Chin. J. Org. Chem. 2006, 26, 354 (in Chinese).

(徐显秀, 魏忠林, 柏旭, 有机化学, 2006, 26, 354.)

[5] Gutnov, A.; Abaev, V.; Redkin, D.; Fischer, C.; Bonrath, W.; Heller, B. Synlett 2005, 1188.

[6] Jiao, L.; Lin, M.; Zhuo, L.-G.; Yu, Z.-X. Org. Lett. 2010, 12, 2528.

[7] (a) Kumar, K. R. R.; Mallesha, H.; Rangappa, K. S. Arch. Pharm. Pharm. Med. Chem. 2003, 336, 159.

(b) Kunz, R. K.; MacMillan, D. W. C. J. Am. Chem. Soc. 2005, 127,3240 .

(c) Kumar, R. S.; Perumal, S.; Shetty, K. A.; Yogeeswari, P.; Sriram, D. Eur. J. Med. Chem. 2010, 45, 124.

(d) Loh, B.; Vozzolo, L.; Mok, B. J.; Lee, C. C.; Fitzmaurice J.; Caddick, S.; Fassati, A. Chem. Biol. Drug Des. 2010, 75, 461.

[8] Grigg, R.; Copper D. M.; Holloway, S.; McDonald, S.; Millington, E.; Sarker, M. A. B. Tetrahedron 2005, 61, 8685.
[9] Shi, J.-W.; Zhao, M.-X.; Lei, Z.-Y.; Shi, M. J. Org. Chem. 2008, $73,305$.

[10] Aria, T.; Yokoyama, N.; Mishiro, A.; Sato, H. Angew. Chem., Int. Ed. 2010, 49, 7895.

[11] Suga, H.; Nakajima, T.; Itoh, K.; Kakehi, A. Org. Lett. 2005, 7, 1431.

[12] Chen, D.-H.; Wang, Z.; Li, J.-T.; Yang, Z.-G.; Lin, L.-L.; Liu, X.-H.; Feng, X.-M. Chem. Eur. J. 2011, 17, 5226.

[13] Sibi, M. P.; Itoh, K.; Jasperse, C. P. J. Am. Chem. Soc. 2004, 126, 5366.

[14] Suga, H.; Adachi, Y.; Fujimoto, K.; Furihata, Y.; Tsuchida, T.; Kakehi, A.; Baba, T. J. Org. Chem. 2009, 74, 1099.

[15] Suga, H.; Funyu, A.; Kakehi, A. Org. Lett. 2007, 9, 97.

[16] Suga, H.; Ishimoto, D.; Higuchi, S.; Ohtsuka, M.; Arikawa, T.; Tsuchida, T.; Kakehi, A.; Baba, T. Org. Lett. 2007, 9, 4362.

[17] Suga, H.; Furihata, H.; Sakamoto, A.; Itoh, K.; Okumura, Y.; Tsuchida, T.; Kakehi, A.; Baba, T. J. Org. Chem. 2011, 76, 7377.

[18] Binger, P.; Lü, Q.-H.; Wedemann, P. Angew. Chem., Int. Ed. 1985, 24,316 .

[19] Tamaki, T.; Ohashi, M.; Ogoshi, S. Angew. Chem., Int. Ed. 2011, 50, 12067.

[20] Yao, B.-B.; Li, Y.; Liang, Z.-J.; Zhang, Y.-H. Org. Lett. 2011, 13, 640.

[21] Wu, X.-X.; Li, L.; Zhang, J.-L. Chem. Commun. 2011, 47, 7824.

[22] Zhang, J.-M.; Chen, Z.-L.; Wu, H.-H.; Zhang, J.-L. Chem. Commun. 2012, 48, 1817.

[23] Reppe, W.; Schichting, O.; Klager, K.; Toepel, T. Justus Liebigs Ann. Chem. 1948, 560, 1.

[24] (a) Aalbersberg, W. G. L.; Barkovich, A. J.; Funk, R. L.; Hillard, R. L.; Vollhardt, K. P. C. J. Am. Chem. Soc. 1975, 97, 5600.

(b) Vollhardt, K. P. C. Acc. Chem. Res. 1977, 10, 1.

(c) Vollhardt, K. P. C. Angew. Chem. 1984, 96, 525.

[25] (a) Duong, H. A.; Louie, J. J. Organomet. Chem. 2005, 690, 5098. (b) Duong, H. A.; Louie, J. Tetrahedron 2006, 62, 7552.

[26] Qiu, Z.-Z.; Xie, Z.-W. Angew. Chem., Int. Ed. 2009, 48, 5729.

[27] Heying, T. L.; Ager, J. W.; Clark, S. L.; Mangold, D. J.; Goldstein, H. L.; Hillman, M.; Polak, R. J.; Szymanski, J. W. Inorg. Chem. 1963, 2, 1089.

[28] Sayler, A. A.; Beall, H.; Sieckhaus, J. F. J. Am. Chem. Soc. 1973, 95, 5790.

[29] Deng, L.; Chan, H.-S.; Xie, Z,-W. J. Am. Chem. Soc. 2006, 128 , 7728.

[30] Qiu, Z.-Z.; Ren, S.-K.; Xie, Z.-W. Acc. Chem. Res. 2011, 44, 299.

[31] Qiu, Z.-Z; Wang, S.-R.; Xie, Z.-W. Angew. Chem., Int. Ed. 2010, $49,4649$.

[32] Ren, S.-K.; Qiu, Z.-Z.; Xie, Z.-W. J. Am. Chem. Soc. 2012, 134, 3242.

[33] Qiu, Z.-Z.; Xie, Z.-W. Angew. Chem., Int. Ed. 2008, 47, 6572.

[34] Qiu, Z.-Z.; Xie, Z.-W. J. Am. Chem. Soc. 2009, 131, 2084.

[35] Tsuda, T.; Morikawa, S.; Sumiya, R.; Saegusa, T. J. Org. Chem. 1988, 53, 3140.

[36] (a) Powell, M. T.; Hou, D.; Perry, M. C.; Cui, X.; Burgess, K. J. Am. Chem. Soc. 2001, 123, 8878.

(b) Perry, M. C.; Cui, X.; Powell, M. T.; Hou, D.-R.; Reibenspies, J. H.; Burgess, K. J. Am. Chem. Soc. 2003, 125, 113.

(c) Chen, T.; Jiang, J.-J.; Xu, Q.; Shi, M. Org. Lett. 2007, 9, 865.

(d) Song, H.; Gu, L.-N.; Zi, G. J. Organomet. Chem. 2009, 694, 1493.

[37] Louie, J.; Gibby, J. E.; Farnworth, M. V.; Tekavec, T. N. J. Am. Chem. Soc. 2002, 124, 15188.

[38] Tekavec, T. N.; Arif, A. M.; Louie. J. Tetrahedron 2004, 60, 7431.

[39] McCormick, M. M.; Duong, H. A.; Zuo, G.; Louie, J. J. Am. Chem. 
Soc. 2005, 127, 5030

[40] Tekavec, T. N.; Zuo, G.; Simon, K.; Louie, J. J. Org. Chem. 2006, $71,5834$.

[41] Tsuda, T.; Kiyoi, T.; Miyane, T.; Saegusa, T. J. Am. Chem. Soc. 1988, $110,8511$.

[42] Tekevac, T. N.; Louie, J. Org. Lett. 2005, 7, 4037.

[43] Kumar, P.; Troast, D. M.; Cella, R.; Louie, J. J. Am. Chem. Soc. 2011, 133, 7719.

[44] Esquivias, J.; Arrayás, R. G.; Carretero, J. C. J. Am. Chem. Soc. 2007, 129, 1480.

[45] (a) Hill, M. D. Chem. Eur. J. 2010, 16, 12052.

(b) Heller, B.; Hapke, M. Chem. Soc. Rev. 2007, 36, 1085.

[46] Ohashi, M.; Takeda, I.; Ikawa, M.; Ogoshi, S. J. Am. Chem. Soc. 2011, 133, 18018.

[47] Nakao, Y.; Morita, E.; Idei, M.; Hiyama, T. J. Am. Chem. Soc. 2011, 133, 3264.

[48] Murakami, M.; Ashida, S.; Matsuda, T. J. Am. Chem. Soc. 2006, $128,2166$.
[49] Ashida, S.; Murakami, M. Bull. Chem. Soc. Jpn. 2008, 81, 885.

[50] Kumar, P.; Zhang, K.; Louie, J. Angew. Chem., Int. Ed. 2012, 51, 8602.

[51] Saito, S.; Masuda, M.; Komagawa, S. J. Am. Chem. Soc. 2004, 126, 10540.

[52] Maeda, K.; Saito, S. Tetrahedron Lett. 2007, 48, 3173.

[53] Yamasaki, R.; Sotome, I.; Komagawa, S.; Azumaya, I.; Masu, H.; Saito, S. Tetrahedron Lett. 2009, 50, 1143.

[54] Nadal, M. L.; Bosch, J.; Vila, J. M.; Klein, G.; Ricart, S.; Moretó, J. M. J. Am. Chem. Soc. 2005, 127, 10476.

[55] Wender, P. A.; Christy, J. P.; Lesser, A. B.; Gieseler, M. T. Angew. Chem., Int. Ed. 2009, 48, 7687.

[56] Saito, S.; Maeda, K.; Yamasaki, R.; Kitamura, T.; Nakagawa, M.; Kato, K.; Azumaya, I.; Masu, H. Angew. Chem., Int. Ed. 2010, 49, 1830.

[57] Nishimura, A.; Ohashi, M.; Ogoshi, S. J. Am. Chem. Soc. 2012, 134, 15692.

(Zhao, C.) 